\title{
Attachment and Differentiation of Human Umbilical Cord Stem Cells on to the Tooth Root Surface with and without the Use of Fibroblast Growth Factor- An In Vitro Study
}

\author{
Joann Pauline George ${ }^{1}$, Pornika Chakravarty ${ }^{1}$, Kamedh Yashawant Chowdhary ${ }^{1}$, \\ H Purushothama ${ }^{2}$, Jyothsna A Rao ${ }^{2}$ \\ ${ }^{1}$ Krishnadevaraya College of Dental Sciences \& Hospital, Hunasamaranahalli, (via) Yelahanka, Krishnadevarayanagar, \\ Bangalore (North), ${ }^{2}$ Sri Raghavendra Biotechnologies Pvt. Ltd. Bangalore, India
}

Background and Objectives: The purpose of this first of its kind study was to analyse the growth, development and attachment of cultured human umbilical cord stem cells alone or supplemented with basic Fibroblast Growth Factor (bFGF) on both healthy and periodontally diseased tooth surfaces in vitro.

Methods: Four groups of 12 root surface scaffolds each were classified as Group I- healthy root surfaces; Group IIperiodontally diseased; Group III- Healthy with bFGF and Group IV- periodontally diseased root with bFGF. bFGF was applied in the concentration of $8 \mathrm{ng} / \mathrm{ml}$ on to the surface followed by incubation of cultured human umbilical cord stem cells (hUCMSCs) on the scaffolds. Scanning electron microscopy observations were made on $14^{\text {th }}$ and $21^{\text {st }}$ days to assess the proliferation and morphology of cells attached on the tooth surface.

Results: Cultured hUCMSCs demonstrated adhesion to tooth root scaffold. All the groups showed a significant increase in the number of cell attachment from $14^{\text {th }}$ day to $21^{\text {st }}$ day. The groups with bFGF showed a significant increase in attachment of cells when compared to the groups without bFGF. The cells showed an increase in number of flat cells from 14th day to 21 st day in all the groups indicating an increased maturity of cells. Periodontally diseased groups had less maturity of cells than healthy groups. The groups supplemented with bFGF, had more mature cells than the groups without bFGF.

Conclusions: hUCMSCs have the propensity to differentiate into cells that have the capacity to bind to root surfaces. hUCMSCs incubated with bFGF showed better proliferation and attachment to tooth root surfaces. The role of hUCMSCs can be further explored for periodontal regeneration.

Keywords: Mesenchymal Stem Cell, Wharton Jelly cells, Multipotent mesenchymal stromal cells, Regeneration, Growth factors

Accepted for publication March 9, 2015, Published online May 30, 2015 Correspondence to Joann Pauline George

Krishnadevaraya College of Dental Sciences \& Hospital, Hunasamaranahalli, (via) Yelahanka, Krishnadevarayanagar, Bangalore International Airport Road, Bangalore (North) - 562157. Karnataka, India

Tel: +91-9448541637, Fax: +9180-28467084

E-mail: drjoannpaulinegeorge@gmail.com

(c) This is an open-access article distributed under the terms of the Creative Commons Attribution Non-Commercial License (http://creativecommons.org/ licenses/by-nc/4.0/), which permits unrestricted non-commercial use, distribution, and reproduction in any medium, provided the original work is properly cited.

\section{Introduction}

Stem cells, directed to differentiate into specific cell types, offer the possibility of a renewable source of replacement cells and tissues to treat diseases (1). Periodontium has limited capacity for regeneration in early phases of the disease (2) because of the lack of robust stem cells. In such a scenario exogenous regenerative 'tools' such as ex vivo expanded/manipulated stem cells can be used to replenish the host cell niche and facilitate tissue regeneration (3). 
Human bone-marrow-derived Mesenchymal Stem Cells (BM-MSCs) that are extensively used in regenerative approaches require a highly invasive harvest procedure and the frequency, proliferation efficiency and differentiation potential of BM-MSCs decline with age.

Foetal or neonatal MSCs appear to be more primitive and have greater multi-potentiality than their adult counterparts and can thus be considered as an alternative source of MSCs. The umbilical cord, which is discarded at birth, can provide an inexhaustible source of stem cells through a non-invasive, painless and ethically noncontroversial collection procedure. The umbilical cord -derived MSCs (hUCMSCs) are more primitive and have faster proliferation rates, wide multi-potency and greater expansion capability compared with adult MSCs and do not induce teratomas (4). Their intermediate state between adult and embryonic stem cells also makes them an ideal candidate for reprogramming to the pluripotent status. The arena of tissue engineering for regeneration requires a scaffold, cells and growth factors. Basic fibroblast growth factor (bFGF) is a potent mitogen for mesenchymal cells and is also known to induce angiogenesis, chemotaxis and proliferation of periodontal ligament cells. bFGF has successfully regenerated periodontal tissues, harnessing the ecto-mesenchymal origin of the periodontium and the presence of undifferentiated mesenchymal cells in the periodontal ligament of adults (5). A regenerative approach that combines the advantages of both hUCMSCs and bFGF can prove beneficial in the management of periodontal defects.

To the best of our knowledge the role of hUCMSCs in the field of periodontal regeneration has not been extensively researched and no studies have evaluated the proliferative/adhesive property of hUCMSCs to root surfaces. Hence in a first of its kind attempt, the capacity of hUCMSCs alone and under the influence of bFGF to differentiate and adhere onto periodontally healthy and diseased tooth root surfaces has been evaluated.

\section{Materials and Methods}

\section{Isolation and culture of Human Umbilical Cord Stem Cells}

The research protocol was approved by the institutional ethical board and review committee of Krishnadevaraya College of Dental Sciences, affiliated to Rajiv Gandhi University of Health Sciences, Bangalore for human sub- jects and the study was conducted in accordance with the Helsinki Declaration of 1975, as revised in 2000. The study protocol was explained to the expectant mothers and a written consent was obtained. Fresh human umbilical cords were obtained from informed healthy mothers in hospitals at the time of delivery, after birth and collected in phosphate buffered saline solution (6). The cords were rinsed twice in phosphate buffered saline in penicillin and streptomycin, and the cord blood was removed during this process. The washed cords were cut into $1-\mathrm{mm}^{2}$ pieces and floated in low-glucose Dulbecco's modified Eagle's medium containing $10 \%$ foetal bovine serum. The pieces of cord were subsequently incubated at $37^{\circ} \mathrm{C}$ in a humidified atmosphere consisting of $5 \% \mathrm{CO}_{2}$. Non-adherent cells were removed by washing. The medium was replaced every 3 days after the initial plating. When well-developed colonies of cells appeared after 10 days, the culture were trypsinized and passaged into a new flask for further expansion (Fig. 1A). All of the infused umbilical cord mesenchymal stem cells were derived from passages $2 \sim 5$, with rigorous purification and quality control (7). UCMSC cellsurface markers were examined using flow cytometry. Cultured UCMSCs showed strong positive staining for CD73, CD44, CD105 and CD 90 (Fig. 1B).

\section{Root slice preparation}

48 scaffolds were collected for the study. 24 periodontally diseased scaffolds were obtained from teeth with proximal attachment loss of $\geq 7 \mathrm{~mm}$ that were indicated for extraction due to poor prognosis. 24 healthy scaffolds were obtained from teeth indicated for orthodontic extraction/surgical dis-impaction from non-smoker and systemically healthy patients. Teeth with root caries or root restorations, root surface abrasions, fracture, demineralized root surfaces, patients who have undergone scaling and root planning or any other type of regenerative periodontal therapy 6 months prior to the initial examination were not included in the study.

\section{Specimen preparation, sectioning and sterilization}

Extraction was performed without traumatizing regions of interest on the root surfaces. The root surfaces were planed with scalers and curettes* to remove any soft connective tissues. All the pulpal tissues in root canals were removed with files ${ }^{\dagger}$. Test specimen of size $16 \mathrm{~mm}^{2}$ (4 $\mathrm{mm} \times 4 \mathrm{~mm}$ ) and thickness of $2 \mathrm{~mm}$ were prepared. The specimens were then sterilized by autoclaving and kept in

\footnotetext{
${ }^{*} \mathrm{Hu}$ Friedyscalers and curettes (Chicago, IL)

${ }^{\dagger}$ Hedstrom and Reamer files (Dentsply)
} 


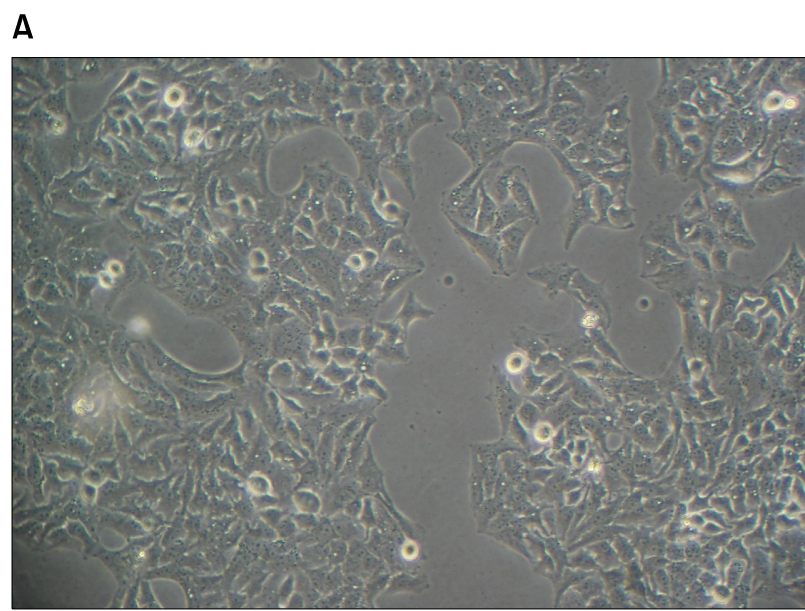

B

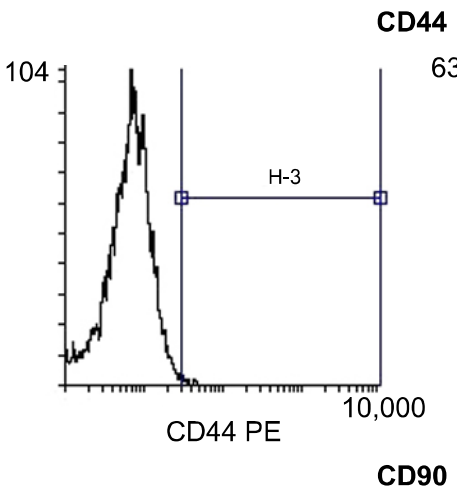

CD44

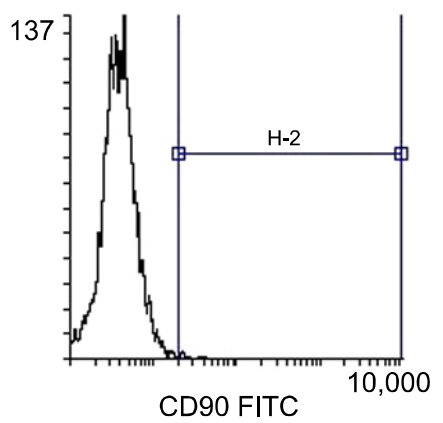

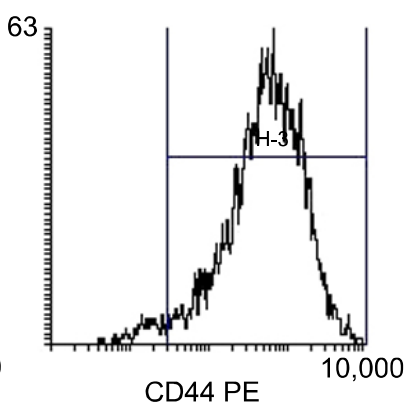

CD44 PE

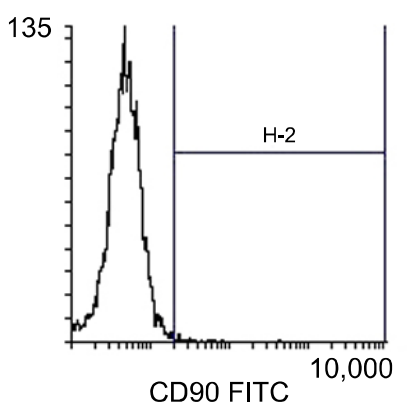

CD73
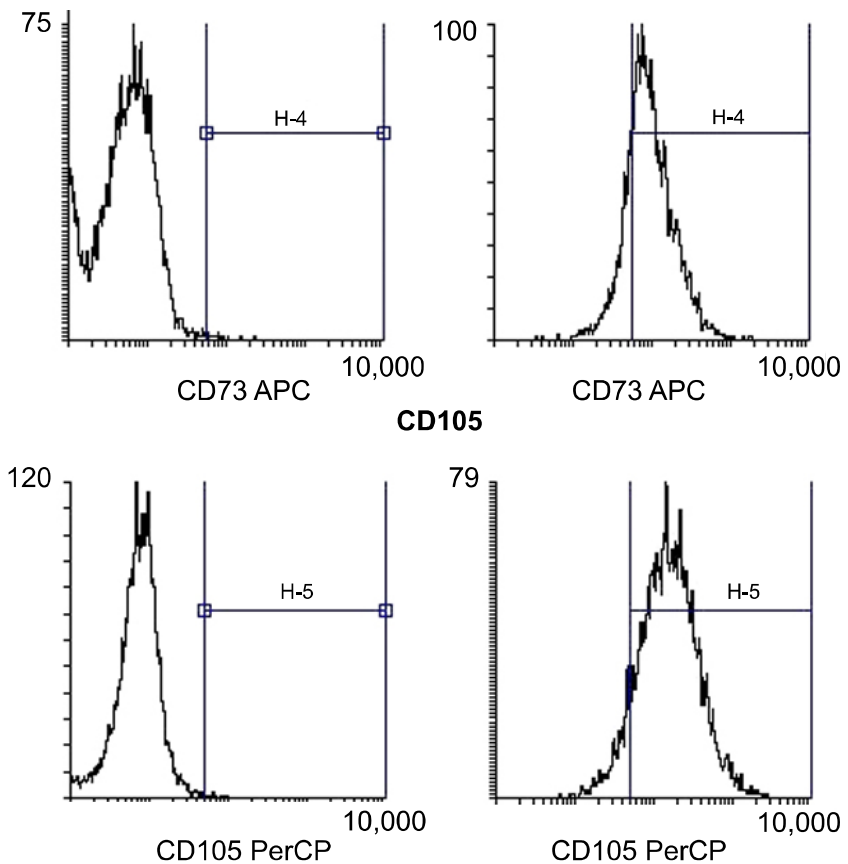

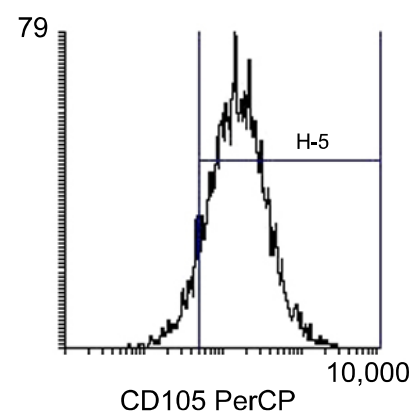

Fig. 1. Wharton's jelly derived human umbilical cord stem cells. (A) Immature hUCMSCs seen as oval/spindle shaped cells in the $3^{\text {rd }}$ passage. (B) Flow cytometry analysis of hUCMSCs after 3 passages of culture showed positive staining for typical mesenchymal markers (CD90, CD105, CD44, CD73).

saline at $4^{\circ} \mathrm{C}$ until further use (6).

The samples were distributed into 4 groups (12 specimens per group)

GROUP-I: hUCMSCs were added to healthy root substrate

GROUP-II: hUCMSCs were added to periodontally diseased root substrate

GROUP-III: hUCMSCs and bFGF were added to healthy root substrate

GROUP-IV: hUCMSCs and bFGF were added to periodontally diseased root substrate

\section{Preparation of bFGF-2}

bFGF- $2^{\dagger}$ was reconstituted by dissolving it in distilled water as per the manufacturer's guidelines. A stock solution was prepared and kept at $-4^{\circ} \mathrm{C}$ until use. $10 \mu \mathrm{g}$

${ }^{\ddagger}$ Genxbio Health Sciences Pvt Ltd, Delhi, India 
of bFGF was mixed in $100 \mu 1$ of distilled water. $10 \mu 1$ Stock solution of bFGF-2 was then prepared with $1 \mu \mathrm{g}$ of growth factor. This solution was then diluted by 100 times to get $1000 \mu 1(1 \mathrm{ml})$ of stock solution with $1 \mu \mathrm{g}(1,000$ $\mathrm{ng}$ ) of growth factor. Thus a concentration of $1 \mathrm{ng} / 1 \mu 1$ of stock solution was prepared, of which $8 \mu 1$ was used for each $\mathrm{ml}$ of media (8).

\section{Cell seeding}

Scaffolds were placed in a petridish with the culture media. Cultured hUCMSCs (Fig. 1) from cell passages 2-5 were pipetted out and seeded onto the scaffolds of all groups at a density of $1 \times 10^{5}$ per sample (6). For Groups III and IV, bFGF was supplemented to the culture media before seeding the cells on the scaffolds. Medium was replaced every 3 days after initial plating. The human umbilical cord mesenchymal stem cells were cultured on the substrates.

\section{Preparation of teeth for SEM Analysis}

Following incubation for the selected time period, scaffolds were gently withdrawn from the tissue culture plates. The substrates were prepared for SEM analysis. Specimens were fixed in 3\% Glutaraldehyde in ice cold Phosphate Buffered Saline for 30 minutes. Further these were immersed in 70\% Ethyl alcohol for 30 mins. This was followed by immersion in $100 \%$ ethanol for 2 hrs. Ethanol was discarded and specimens were again fixed in $100 \%$ fresh ethanol overnight. Next day they were kept in fresh solution of $100 \%$ ethanol for 1 hour. This was followed by immersion in amyl acetate solution for 2 hours Specimens were then critical point dried with liquid $\mathrm{CO}_{2}$ (6). Gold sputtering $\$$ was done just prior to SEM Analysis. Once processing was completed, scaffolds were placed in $\mathrm{SEM}^{* *}$ for viewing and photographing at $\times 500$. A grid was placed over the images, to facilitate cell counting, repeated cell counts of the number of cells attached to the tooth surface were performed by a blinded observer and each photograph had 5 representative areas, one central and 4 peripheral. In addition the morphology of individual cells were assessed at a magnification of $\times 500$ and were scored using a scale from 1 to 4 , where $1=$ flat cells, $2=$ combination of oval or round and flat cells, $3=$ oval cells and $4=$ round cells (9). The parameters that were assessed and compared between the groups were number of cells on the scaffold and the morphological score of the adhereing cells.

\section{Statistical Analysis}

The Students ' $\mathrm{t}$ ' test was used to determine whether there was a statistical difference between Control and Study group in the parameters measured. One way analyses of variance with Tukey's post hoc test were used to determine the difference of group wise comparisons.

\section{Results}

The purpose of this present study was to determine the ability of hUCMSCs to differentiate into cells either in the presence or absence of bFGF and its ability to adhere to scaffolds derived from periodontally diseased and healthy root surfaces of human teeth in vitro at two different time periods (Day 14 and Day 21).

\section{Cell proliferation assay}

ANOVA was done to compare the attachment of cells on all the four groups to test the null hypothesis. The ' $p$ ' value was less than 0.05 which signifies that the null hypothesis being tested in the study, that umbilical cord stem cells differentiate into fibroblasts or fibroblast like cells and attach to the root surfaces, is accepted and all the groups show attachment of cells. Group I, Group III and Group IV showed a significant increase in the attachment of cells from 14th to 21st day ('p' value $0.02,0.03$ and 0.001 respectively). In group II, there was increase in attachment of cells from 2.2 cells/unit area to 3.4 cells/ unit area, from Day 14 to Day 21 (Graph 1).

On day 14 when all the groups were compared by ANOVA ' $F$ ' test, a statistically significant ' $p$ ' value of 0.013 was achieved. There was a statistically significant increase of cells in Group-III as compared to Group-I with a ' $p$ ' value of 0.04 . When Group-I was compared with Group-II and Group-IV, statistically insignificant results with ' $p$ ' value of 0.98 and 0.06 respectively. Comparison of Group-II with Group-III and IV gave statistically insignificant result with 'p' value of 0.07 and 0.12 . Comparison of Group III and IV had a 'p' value of 0.99 which was statistically not significant (Graph 1, Fig. 2).

On Day 21 when all the groups were compared by ANOVA ' $F$ ' test, a statistically significant result of 'p' value of 0.003 was achieved which implies that all the groups showed attachment of cells. A statistically significant increase in attachment of cells was seen in Group-III and Group-IV as compared to Group-II with a 'p' value of 0.009 and 0.004respectively. Comparison of Group-III and

§J.F.C. 1100 JEOL

${ }^{* *}$ FEl Quanta 200, Scanning Electron Microscope, USA 

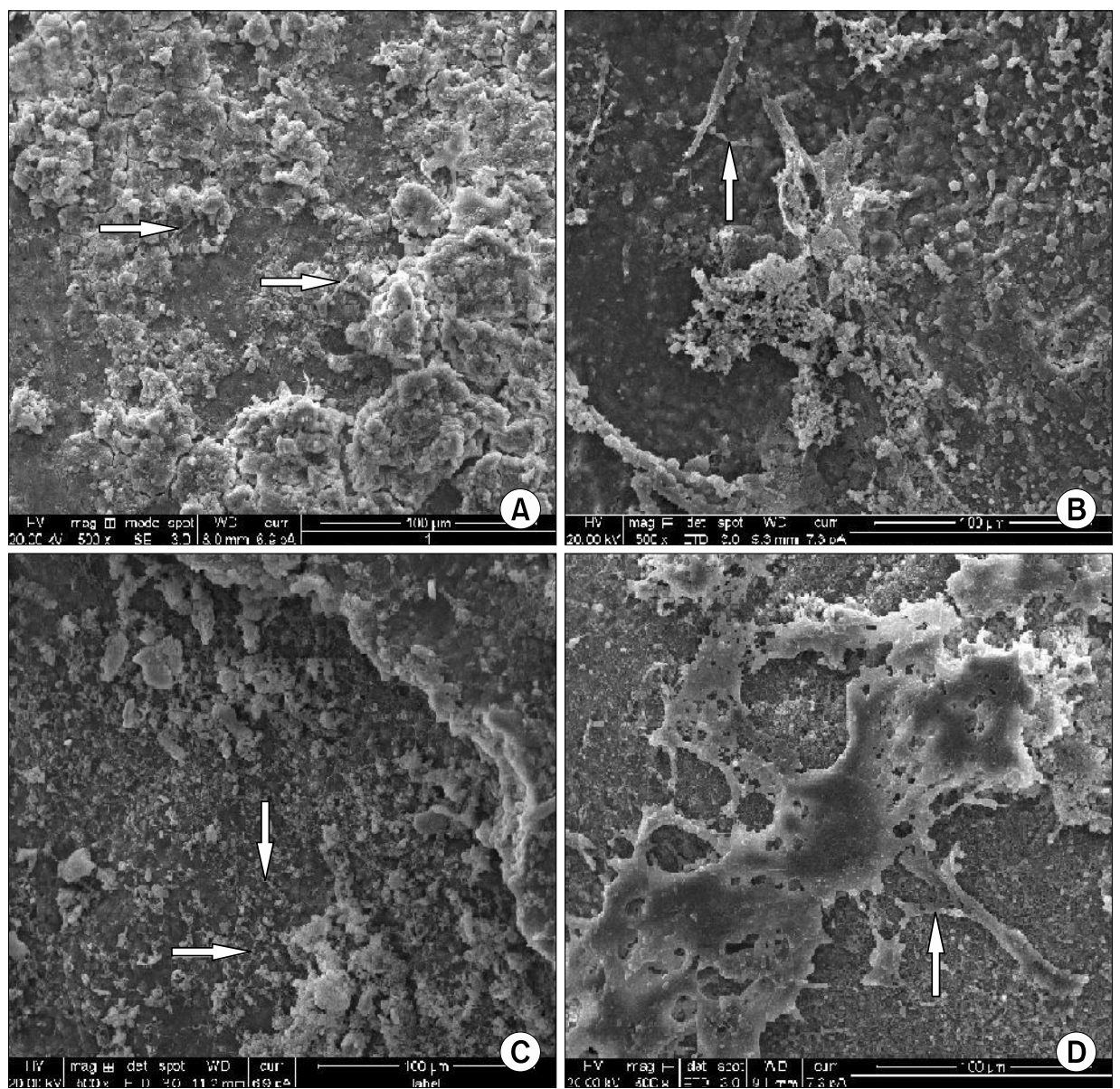

Fig. 2. SEM analysis at 500X magnification showing cellular morphology on Day 14 . (A) $14^{\text {th }}$ Day scaffold for Group I showing presence of spindle shaped cells (white arrow). (B) $14^{\text {th }}$ Day scaffold for Group II scaffold depicts round cells (white arrow). (C) $14^{\text {th }}$ Day scaffold for Group III shows presence of spindle shaped cells (white arrow). (D) $14^{\text {th }}$ Day scaffold for Group IV shows presence of spindle shaped cells (white arrow).

IV gave a ' $p$ ' value of 0.98 and this did not show a statistically significant result, When Tukeys test was done to compare Group-I with Group-II, III and IV, statistically insignificant result was seen with ' $p$ ' value of $0.3,0.3$ and 0.17. (Graph 1, Fig. 3).

\section{Cell morphology assay}

In group I significant difference with a 'p' value of 0.014 was seen showing a decrease in morphology score from 14th to 21st day. In group II reduction in mean score was seen from 1.1 to 0.8 from Day 14 to Day 21 suggesting change of morphology from round to flat. Reduction of score from 1.2 to 0.93 was seen in group III. Group IV showed reduction in score from 1.06 to 0.9 indicating conversion to a more mature flat morphology of fibroblast (Graph 2).

On day 14 the mean score of morphology of the cells in Group-I was 1.6, in Group-II 1.1, Group-III showed 1.2 and Group-IV showed 1.06 (Fig. 2). On day 21 the mean score decreased for all the groups. The mean score for Group-I was 0.9, Group-II was 0.8, Group-III had 0.93, and Group-IV had 0.9.This implies maturation of cells from $14^{\text {th }}$ day to $21^{\text {st }}$ day (Graph 2, Fig. 3).

\section{Discussion}

Regeneration requires the formation of new cementum on root surface, new alveolar bone and periodontal ligament fibres making functional connection between the two mineralized tissues Adhesion of cells to the root surface is one of the essential processes along with cell migration for an oriented and functional attachment (8). BM-MSCs, and embryonic stem cells (ESCs) have demonstrated the possibility of creating dental tissue replacements from non-dental stem cells by imitating embryonic development mechanisms. MSCs have been procured from human delivery wastes, such as cord blood, umbilical cord tissue and placenta (10). bFGF serves as a potent mitogen and elevates the level of cyclin D protein and cyclin dependent kinase, which drives the cells into S phase (10), thus modulating the hUCMSCs population growth kinetics.

Hence the primary objective of the study was to assess 

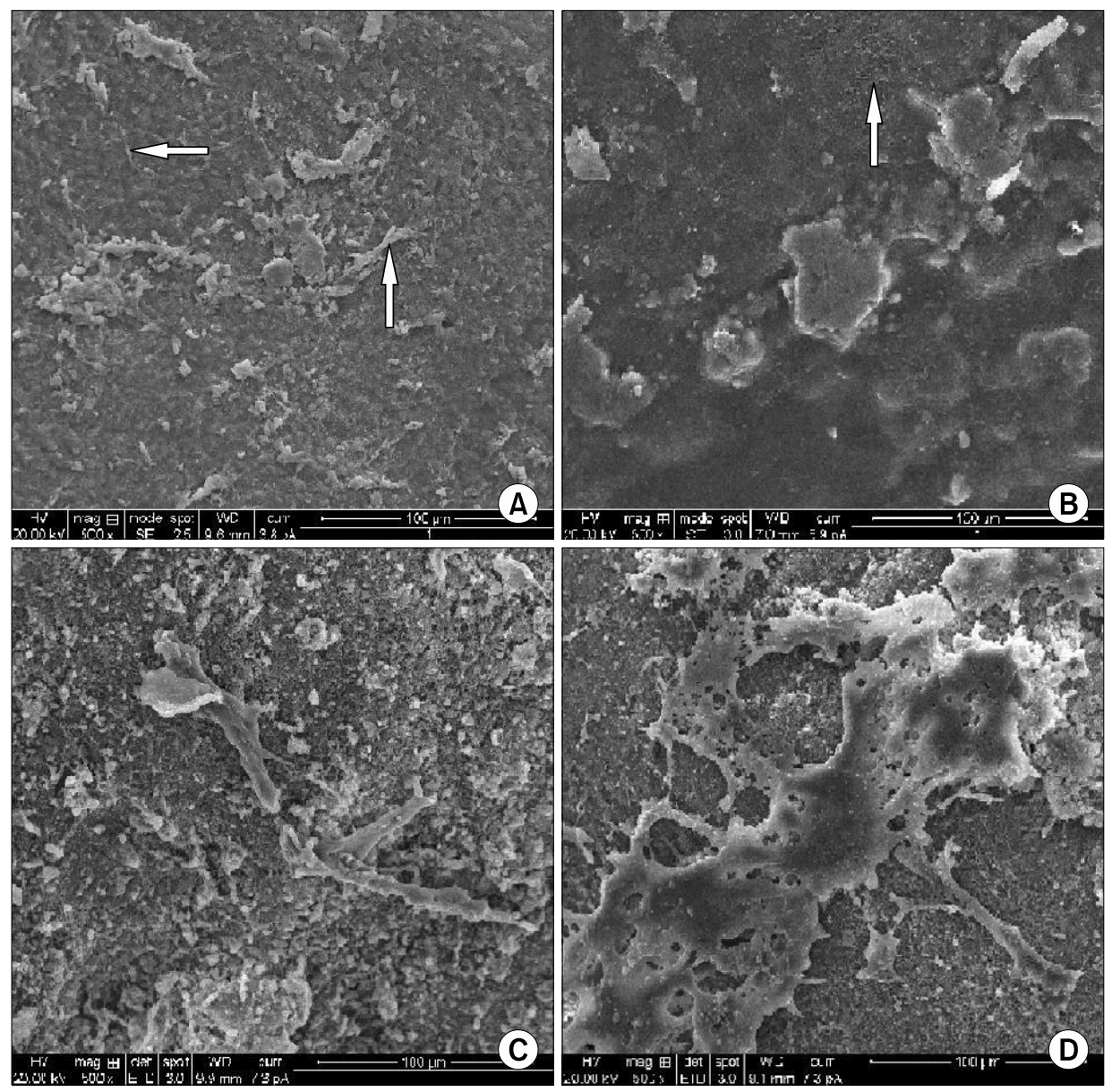

Fig. 3. SEM analysis at 500X magnification showing cellular morphology on Day 21. (A) $21^{\text {st }}$ Day scaffold for Group I showing cells with flat morphology (white arrow). (B) $21^{\text {st }}$ Day scaffold for Group II shows cells with flat morphology (white arrow). (C) $21^{\text {st }}$ Day scaffold for Group III show cytoplasmic processes of cells (white arrow). (D) $21^{\text {st }}$ Day scaffold for Group III show cytoplasmic processes of cells (white arrow).

the proliferative capacity of hUCMSCs with and without bFGF and the attachment of these cells to tooth root surface. There are no previous studies reported in the scientific literature that have evaluated the propensity of hUCMSCs to differentiate into cells that attach to tooth root surfaces.

The osteogenic, adipogenic potential and immunosuppressive activity of these cells is not altered by bFGF (10). Infact bFGF supplementation encourages BM-MSCs differentiation to osteogenic and adipogenic phenotype and enhances the immunosuppressive activity $(11,12)$. bFGF also preserves the primitive status of hUCMSCs, reduces cell death, decreases the secretion of Vascular Endothelial Growth Factor and MMP-3 (10).

One of the primary pre-requisites of optimum periodontal regeneration is to increase the cellular machinery i.e., the MSC directly in sites that requires regeneration (13). hUCMSCs have great proliferative potential and can differentiate into different cell types depending on the inductive media (14).

Attachment of cells to the root surface is very important to obtain newly formed periodontal ligament which is a non-mineralised connective tissue between two mineralised tissues i.e. bone and cementum (15). In a study done by Inac et al. 2009 that evaluated the in vitro differentiation of human embryonic stem cells on tooth surface (8) a formation of soft - hard tissue relationship in close contact areas was noted. ESCs acquired fibroblast like morphology, formed tissue like deposits on cementum surfaces and occasional embryonic body like structures.

Li et al. 2013 successfully isolated cells from Wharton's jelly of umbilical cord, principally exhibiting a fibroblast like morphology (14). These cells expanded rapidly reaching 80 90\% confluence in 19 days. In groups supplemented with bFGF, increased number of cell proliferation was seen. This further reiterates the important role played by $\mathrm{bFGF}$ as an inductive media in propelling hUCMSCs into a more committed lineage of differentiation. This role of bFGF in inducing the proliferation of fibroblast or fibroblast like cells has also been noted by Ramasamy. He also mentioned that bFGF preserves the primitive status of UCMSC by increasing expression of NANOG, Sox 2 and 


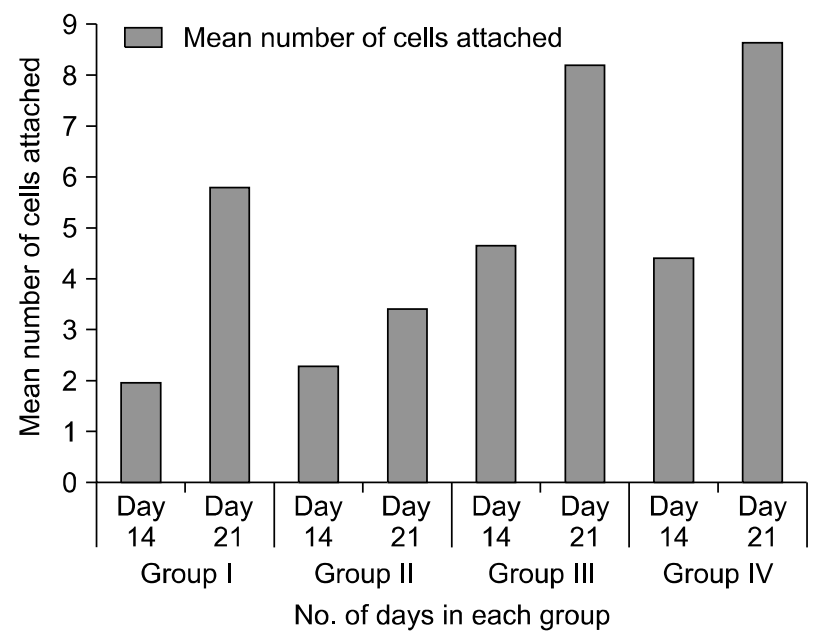

Fig. 4. Graph showing the difference in cellular counts on Day 14 and Day 21 in all the groups. Student ' $\mathrm{t}$ ' test done to evaluate the number of adherent cells on root specimens in all groups between 14th and 21st day. Day 21 day showed a higher number of cell attachment. Data significant when ' $p$ ' value $<0.05$.

Rexl transcription factors (10).

When Paired ' $\mathrm{t}$ ' test was done to assess proliferation of cells from day 14 to day 21, all the groups showed a significant increase in attachment of cells, suggesting the high proliferative capacity of hUCMSCs. The proliferated cells also demonstrated the ability to attach to tooth root surface as initially hypothesised in the study. On day 14, when Group I was compared with Group III, Group III showed a significant increase in attachment of cell number in accordance with the studies done by Hagmann et al and Ramasamy et al. $(10,16)$ Increase in attachment of cells was also seen in Group IV as compared to Group II, showing the mitogenic and proliferative effect of fibroblast growth factor (Fig. 4) (17).

On day 21, similar results were seen. Group III and Group IV showed significantly higher attachment of cells than Group II. Both these groups were under the inductive influence of $\mathrm{b}$ FGF.

On day 14, when Group III was compared with Group IV there was a decrease in attachment of cells in periodontally diseased root surfaces (Group IV). This could be attributed to the presence of rough surfaces with sharp edges of the periodontally diseased surfaces, due to presence of calculus and debris that could damage the cell membranes leading to diminished cell viability (18). Similar observation was seen on day 21 with more number of cells attached in Group I than Group II. The increased number of cells in Group I may be explained by the root surface biocompatibility of healthy tooth root surfaces as compared to diseased tooth surfaces. The decreased cel-

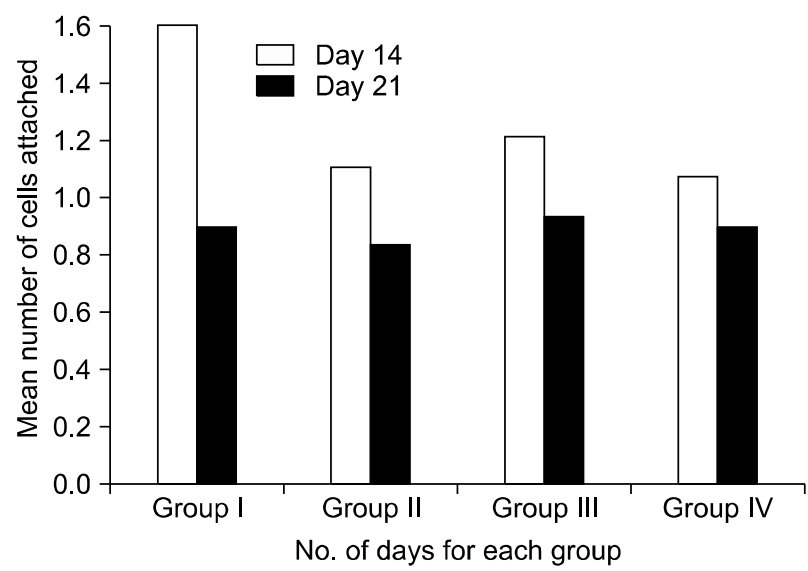

Fig. 5. Graph showing morphologic analysis assessment between all the groups on Day 14 and Day 21. A lesser score with more number of flat cells was seen in day 21.

lular adhesion to diseased root surface is similar to a study conducted by Belal et al. 2006 where the effectiveness of PDGF-BB application on periodontally diseased root surfaces was assessed through attachment and growth of fibroblast cells. The diseased group showed the least number of cell attachment as compared to the healthy and scaling and root planing group. The presence of rough blebs and some debris on the root surfaces of diseased samples may hinder PDL fibroblast cell attachment and growth, and thus explained the presence of incompatible root surfaces in this group (6).

When comparison between Group I and Group II was done, increased attachment of cells was seen in Group II on day 14 and comparison between Group III and Group IV showed profound cell attachment in Group IV on day 21. Procedural effects- such as solutions or sterility of slides maybe responsible for this difference, as also noted by Gamal et al. 1998 (9). Some samples even showed microbial contamination which might have prevented the attachment of cells and it was decided not to count specimens without cell growth.

It is important to understand the morphological changes that occur during the growth and maturation of cells on a suitable biocompatible substrate. Flat cells with numerous attachment extensions and lamellipodia are generally firmly attached and round cells are poorly attached (19).

In the current study, all the groups showed presence of round and oval cell morphology on day 14. Cells isolated from the Wharton's jelly displayed a typical fibroblast like morphology which is in accordance with $\mathrm{Li}$ et al. (14). However, Group I had the maximum mean score of 1.6 suggesting highest percentage of round and oval cells, followed by Group III with a mean score of 1.2 which sug- 
gests the presence of more of flat cells. Similarly, there was a lesser score for Group II, which was 1.1 suggesting more of round or oval cells as compared to a score of 1.06 for Group IV showing more number of flat cells, suggesting the positive influence of bFGF on the differential potential of cells (Fig. 5). Studies have demonstrated that human Dental Pulp Cells when cultured with the medium containing bFGF, were highly proliferative and capable of differentiating in vitro into osteoblasts, chondrocytes, and adipocytes (20). Stem cells from the apical papilla (SCAP) a type of mesenchymal stem cells found in the developing tissue, apical papilla, of immature permanent teeth when expanded in the presence of bFGF for 1 week in subsequent stimulation of the osteogenic/dentinogenic condition resulted in enhanced differentiation (21).

On day 21, most of the cells in all the groups showed flat morphology with similar mean scores, which indicates that the cells proliferated into mature cells in 21 days.

Hence it can be concluded that hUCMSCs can differentiate into cells and attach on tooth surfaces and the supplementation with bFGF enhances the proliferation and attachment of the cells. The morphology of these cells are similar to fibroblasts and show increase in maturity with addition of bFGF.

\section{Conclusion}

Previous studies have reported that human umbilical cord tissue demonstrates the advantages of providing an abundant supply of cells from donors via a non-invasive procedure with a low risk of infection and can therefore be considered an attractive alternative source of MSCs. hUCMSCs can differentiate into cells that possess the fibroblast-like morphology, non-hematopoietic cell surface phenotypes, low immunogenicity, and multipotent differentiation ability. Therefore, MSCs obtained from human umbilical cord tissue may serve as a rational candidate cell source for tooth regeneration research. Signalling molecules are another important element in periodontal regeneration. Growth factors when added can modulate many cellular activities, including cell differentiation and proliferation, cell migration and extracellular matrix synthesis and production. bFGF is one such bioactive agent that can promote periodontal regeneration. Although there are many challenges ahead of us in terms of utilizing stem cells for tissue regeneration, hUCMSCs are one of the most promising postnatal stem cell populations for tissue repairing and regeneration.

Future research can be targeted at characterization of these differentiated cells and better define their role in pe- riodontal regeneration. Other signalling molecules related to osteogenesis also can be studied in combination with hUCMSCs. The propensity for this promising cellular machinery hUCMSCs, in periodontal regeneration needs to be further researched.

\section{Acknowledgments}

Authors would like to thank Dr. Prabhuji MLV \&Dr. Radhika MB for their constant support and guidance. Authors would also like to thank Jagannatha $\mathrm{P}$ for his contribution in the statistical analysis. A special note of thanks to Dr.Himani Gupta for the help rendered by her during the research work.

\section{Potential conflict of interest}

The authors have no conflicting financial interest.

\section{References}

1. Mudda JA, Bajaj M. Stem cell therapy: a challenge to periodontist. Indian J Dent Res 2011;22:132-139

2. Shi S, Bartold PM, Miura M, Seo BM, Robey PG, Gronthos S. The efficacy of mesenchymal stem cells to regenerate and repair dental structures. Orthod Craniofac Res 2005; 8:191-199

3. Chen FM, Sun HH, Lu H, Yu Q. Stem cell-delivery therapeutics for periodontal tissue regeneration. Biomaterials 2012;33:6320-6344

4. Taghizadeh RR, Cetrulo KJ, Cetrulo CL. Wharton's Jelly stem cells: future clinical applications. Placenta 2011;32 Suppl 4:S311-S315

5. Kitamura $M$, Akamatsu $M$, Machigashira $M$, Hara $Y$, Sakagami R, Hirofuji T, Hamachi T, Maeda K, Yokota M, Kido J, Nagata T, Kurihara H, Takashiba S, Sibutani T, Fukuda M, Noguchi T, Yamazaki K, Yoshie H, Ioroi K, Arai $\mathrm{T}$, Nakagawa $\mathrm{T}$, Ito $\mathrm{K}$, Oda $\mathrm{S}$, Izumi $\mathrm{Y}$, Ogata $\mathrm{Y}$, Yamada S, Shimauchi H, Kunimatsu K, Kawanami M, Fujii T, Furuichi Y, Furuuchi T, Sasano T, Imai E, Omae M, Yamada S, Watanuki M, Murakami S. FGF-2 stimulates periodontal regeneration: results of a multi-center randomized clinical trial. J Dent Res 2011;90:35-40

6. Belal $\mathrm{MH}$, Watanabe $\mathrm{H}$, Ichinose $\mathrm{S}$, Ishikawa I. A time-dependent effect of PDGF-BB on adhesion and growth of cultured fibroblasts to root surfaces. Oral Dis 2006;12:543-552

7. Sun L, Wang D, Liang J, Zhang H, Feng X, Wang H, Hua B, Liu B, Ye S, Hu X, Xu W, Zeng X, Hou Y, Gilkeson GS, Silver RM, Lu L, Shi S. Umbilical cord mesenchymal stem cell transplantation in severe and refractory systemic lupus erythematosus. Arthritis Rheum 2010;62:2467-2475

8. Inanç B, Elçin AE, Elçin YM. In vitro differentiation and attachment of human embryonic stem cells on periodontal tooth root surfaces. Tissue Eng Part A 2009;15:3427-3435

9. Gamal AY, Mailhot JM, Garnick JJ, Newhouse R, Sharawy MM. Human periodontal ligament fibroblast response to 
PDGF-BB and IGF-1 application on tetracycline HCI conditioned root surfaces. J Clin Periodontol 1998;25:404-412

10. Ramasamy R, Tong CK, Yip WK, Vellasamy S, Tan BC, Seow HF. Basic fibroblast growth factor modulates cell cycle of human umbilical cord-derived mesenchymal stem cells. Cell Prolif 2012;45:132-139

11. Sotiropoulou PA, Perez SA, Salagianni M, Baxevanis CN, Papamichail M. Characterization of the optimal culture conditions for clinical scale production of human mesenchymal stem cells. Stem Cells 2006;24:462-471

12. Neubauer $M$, Hacker $M$, Bauer-Kreisel $P$, Weiser $B$, Fischbach C, Schulz MB, Goepferich A, Blunk T. Adipose tissue engineering based on mesenchymal stem cells and basic fibroblast growth factor in vitro. Tissue Eng 2005;11: 1840-1851

13. Muschler GF, Nakamoto C, Griffith LG. Engineering principles of clinical cell-based tissue engineering. J Bone Joint Surg Am 2004;86-A:1541-1558

14. Li TX, Yuan J, Chen Y, Pan LJ, Song C, Bi LJ, Jiao XH. Differentiation of mesenchymal stem cells from human umbilical cord tissue into odontoblast-like cells using the conditioned medium of tooth germ cells in vitro. Biomed Res Int 2013;2013:218543

15. Bluteau G, Luder HU, De Bari C, Mitsiadis TA. Stem cells for tooth engineering. Eur Cell Mater 2008;16:1-9

16. Hagmann S, Moradi B, Frank S, Dreher T, Kämmerer PW,
Richter W, Gotterbarm T. FGF-2 addition during expansion of human bone marrow-derived stromal cells alters MSC surface marker distribution and chondrogenic differentiation potential. Cell Prolif 2013;46:396-407

17. Murakami S. Periodontal tissue regeneration by signaling molecule(s): what role does basic fibroblast growth factor (FGF-2) have in periodontal therapy? Periodontol 2000 2011;56:188-208

18. Feist IS, De Micheli G, Carneiro SR, Eduardo CP, Miyagi $S$, Marques MM. Adhesion and growth of cultured human gingival fibroblasts on periodontally involved root surfaces treated by Er:YAG laser. J Periodontol 2003;74:1368-1375

19. Hakki SS, Korkusuz P, Berk G, Dundar N, Saglam M, Bozkurt B, Purali N. Comparison of Er,Cr:YSGG laser and hand instrumentation on the attachment of periodontal ligament fibroblasts to periodontally diseased root surfaces: an in vitro study. J Periodontol 2010;81:1216-1225

20. Morito A, Kida Y, Suzuki K, Inoue K, Kuroda N, Gomi $\mathrm{K}$, Arai T, Sato T. Effects of basic fibroblast growth factor on the development of the stem cell properties of human dental pulp cells. Arch Histol Cytol 2009;72:51-64

21. Wu J, Huang GT, He W, Wang P, Tong Z, Jia Q, Dong L, Niu Z, Ni L. Basic fibroblast growth factor enhances stemness of human stem cells from the apical papilla. J Endod 2012;38:614-622 